Vol. 22 N.1 de 2019 ISSN: 1516-8182

Recebimento: 10/08/2018

Aceite: 18/10/2018

DOI: $10.25059 / 2527-2594 /$ retratosdeassentamentos/\%Y.v\%vi\%i.333

\title{
A definição do espaço rural como local para o desenvolvimento territorial
}

\begin{abstract}
RESUMO: A classificação dos territórios em rurais e urbanos ainda é uma definição necessária para descrever a geografia dos países e subsidiar os elaboradores de políticas públicas para as necessidades do local e para orientar a sociedade em ações específicas naquele território. O objetivo deste trabalho é levantar o que é rural e o que é urbano para auxiliar na implantação de políticas públicas que levem ao desenvolvimento do território. Para isso, este trabalho buscou na literatura quais são os critérios adotados pelos países e organizações para determinar o que qualifica um espaço territorial como rural e uma área como urbana. Para os estudos pesquisados, constatou-se a preocupação em elaborar uma definição espacial e não apenas setorial a respeito do rural e do urbano. Para o Brasil os trabalhos consultados demonstram que existe uma grande parcela da população que vive em áreas que não são claramente rurais ou urbanas. Isto gera dificuldades na elaboração de políticas públicas que estimulem projetos que valorizam o local dentro de um processo de desenvolvimento econômico e social. Pequenas mudanças na forma de classificar esses territórios poderão trazer grandes impactos sobre quem nele vive. Cabe aos pesquisadores e os formuladores de políticas públicas a tarefa de escolher qual a melhor definição do que é o espaço rural para a execução dessas políticas de desenvolvimento do território.
\end{abstract}

Palavras-Chave: Território Rural;Território Urbano; Políticas Públicas.

Abstract :The classification of rural and urban territories is still a necessary definition to describe the geography of the countries and to subsidize the public policy makers for the local needs and to guide society in specific actions in that territory. The objective of this work is to raise what is rural and what is urban in order to allow the implementation of public policies that lead to the development of the territory. In order to do this, this work sought in the literature what are the criteria adopted by countries and organizations to determine what qualifies a territorial space as rural and an area as urban. For the studies researched the concern was to elaborate a spatial and not only sectorial definition regarding the rural and the urban. For Brazil, the works consulted show that there is a large part of the population living in areas that are not clearly rural or urban. This creates difficulties in the implementation of public policies that stimulate projects that value the place within a process of economic and social development. Small changes in the way these territories are classified can have major impacts on who lives in it. It is the task of researchers and policy-makers to choose the best definition of what the rural area is for the implementation of these land development policies.

Keywords: Rural Territory; Urban Territory;Public Policies.

\footnotetext{
${ }^{1}$ Doutorando do PPG em Desenvolvimento Territorial e Meio Ambiente na Universidade de Araraquara (Uniara) e docente na Faculdade de Tecnologia de Catanduva/SP. E-mail: daltro_cella@yahoo.com.br

${ }^{2}$ Docente do PPG em Desenvolvimento Territorial e Meio Ambiente da Universidade de Araraquara (Uniara). E-mail: oqueda@usp.br

${ }^{3}$ Coordenadora e Docente do PPG em Desenvolvimento Territorial e Meio Ambiente da Universidade de Araraquara (Uniara). E-mail: vbotta@techs.com.br
} 


\section{INTRODUÇÃo}

O objetivo deste trabalho é contribuir para o entendimento do que é rural e o que é urbano para assim possibilitar a implantação de políticas públicas que levem ao desenvolvimento de territórios. Para isso, este trabalho buscou na literatura quais são os critérios adotados pelos países e organizações para determinar o que qualifica um espaço territorial como rural e uma área como urbana.

O espaço territorial rural é o local onde ocorre a mescla de atividades econômicas, hábitos e culturas. Até o século XX, o espaço rural era tido como sinônimo de agricultura ou produção primária, caracterizado por uma área de privações e de escassez de recursos. Essa imagem contrastava com o urbano, que era associado ao desenvolvimento, ao progresso e a uma melhor qualidade de vida. Essa era uma visão simplista a respeito do conceito de rural, considerando-o apenas como oposto ao modo de vida urbano.

O desenvolvimento rural depende da interação da agricultura com outras atividades econômicas, como a indústria, o comércio, o artesanato, e os serviços. Portanto, a agricultura tem que estar inserida no contexto do território, pois envolve trabalho, preservação dos recursos naturais paisagísticos e do meio ambiente. Assim, o território é o local de interação entre os atores e setores proativos da economia.

Para Kageyama (2008) há duas ideias sobre o que é rural: uma que ruralidade tem na sua essência a questão geográfica e a outra que rural é uma área afastada ou isolada. Dessa forma, o rural poderia ser entendido como uma região mais distante, especializada na produção primária (agricultura, pesca, pecuária), com baixa densidade populacional, pobres, conservadoras e com dificuldades para se ajustar aos sinais do mercado.

De acordo com Kageyama (2008), os critérios mais utilizados para definir área rural são o tamanho da população e a sua densidade. Mas há muitas controvérsias sobre esses critérios simplificados da definição do que é rural. Os aspectos demográficos são necessários, mas não suficientes para essa definição, uma vez que muda muito entre regiões mais densamente povoadas para regiões menos povoadas. Além dos aspectos demográficos devem-se considerar também os elementos econômicos, sociais e culturais.

A menor densidade populacional permite, segundo Abramovay (2000) aos habitantes do território reduzir o sentimento de solidão causado pelo anonimato da vida metropolitana, melhorando e recuperando as relações familiares, comunitárias e de vizinhança. Ou seja, há um aumento no sentimento de pertencimento daquele território. Para Abramovay (2000, p.13) estes valores podem "transformar-se em fontes de desenvolvimento e a geração de renda vai depender tanto da organização dos habitantes e das instituições rurais, como, sobretudo, do tipo de relação que 
conseguem estabelecer com as cidades".

Os elementos que definem o que é rural, segundo Kageyama (2008), foram se adaptando com a evolução da sociedade e com a maior ocupação dos territórios pelas propriedades rurais de diferentes tamanhos. A modernização da agricultura por meio da adoção da tecnologia nos sistemas de produção, associado ao atendimento das demandas da indústria de processamento da produção primária, possibilitou uma maior aproximação cultural entre os habitantes do campo e das cidades, ampliando o entendimento do que é o território rural e urbano. Essa aproximação explica o aumento da interdependência das atividades produtivas e de serviços entre o campo e as cidades.

Em seu trabalho para o Instituto de Pesquisas Econômicas Aplicadas (Ipea), Abramovay (2000), questiona como a questão demográfica, econômica, política e cultural do meio rural brasileiro seleciona quem nele permanece. Confronta com o que ocorreu nos países capitalistas centrais, onde o meio rural teve participação ativa no desenvolvimento econômico e social destas nações e, seu dinamismo não foi obstáculo à criação de novas vagas de trabalho. Diferentemente do Brasil em que as áreas rurais são aquelas que se encontram fora do limite das cidades e são vistas por parte da sociedade brasileira como um local de atraso nas condições de desenvolvimento. Enquanto predominar este tipo de pensamento no Brasil, será difícil explicar que as áreas rurais podem ser dinâmicas e desenvolvidas. $\mathrm{Na}$ América Latina e no Brasil o que deve ocorrer é um esforço procurando entender as relações entre as regiões rurais e as cidades de que dependem, sem considerar o desenvolvimento como algo exclusivo das regiões urbanizadas. A ruralidade é um conceito de natureza territorial e multisetorial onde se devem levar em consideração as economias regionais e a densidade populacional.

Para Kageyama (2004), rural não é sinônimo de agrícola e nem exclusivo deste; o rural envolve pluriatividades e é multifuncional (funções produtiva, ambiental ecológica e social); apresenta baixa densidade populacional; e, não há isolamento entre os espaços rurais e urbanos, pois há uma rede que envolve os espaços rurais e urbanos por meio de atividades comerciais, sociais e institucionais.

Segundo Abramovay (p.26, 2000), "a ruralidade não é uma etapa do desenvolvimento social a ser superada com o avanço do progresso e da urbanização". A noção de desenvolvimento tem que estar vinculado a valorização da ruralidade por toda a sociedade contemporânea. Pois o espaço rural é uma forma das pessoas aumentarem sua relação com a natureza; habitar em áreas menos povoadas; e, também um local que pode apresentar uma maior inserção nas dinâmicas urbanas.

Nesse contexto, a agricultura desempenha um papel importante nas dinâmicas regionais aumentando a relação cidade-campo, mercado interno e externo. Assim, 
o importante é compreender a dinâmica de desenvolvimento de uma região, sem que ocorra um afastamento das interações com as aglomerações urbanas.

\section{Metodologia}

A consecução dos objetivos pretendidos para esta pesquisa demandou um estudo bibliográfico acerca do tema central, ou seja, o espaço rural. Assim, procurouse resgatar e aprofundar a compreensão acerca do ambiente rural. Esta revisão teórica apresenta uma reflexão sobre as especificidades do que é o espaço rural. Posteriormente discutiu a problemática econômica e social relacionada a este meio no Brasil e no mundo sob as condições de desenvolvimento do território.

\section{AS DIFERENTES FORMAS DE DEFINIR O ESPAÇO RURAL NO MUNDO}

Não há uma única forma de definir o que é o espaço rural no mundo, pois os conceitos de rural e urbano são multidimensionais. Às vezes, a densidade populacional é a preocupação determinante, em outros casos é o isolamento geográfico. Outras vezes, o pequeno tamanho da população caracteriza um lugar rural, mas o quão pequeno é o rural?

Analisando a literatura a respeito da densidade populacional e seus impactos nas relações sociais nos Estados Unidos e na França, Abramovay (2000), concluiu que em locais de maior dispersão populacional há limites no aproveitamento de oportunidades e de desenvolvimento. Isso ocorre devido aos baixos indicadores sociais e situações geográficas preocupantes, tais como o envelhecimento da população e a masculinização do território rural. Esta situação de envelhecimento e predominância masculina, também foi observada no Brasil por meio da análise do Censo do Instituto Brasileiro de Geografia e Estatística (IBGE). Por outro lado, há uma tendência, especialmente em países desenvolvidos e em desenvolvimento, de uma intensificação da migração de famílias de média e alta renda e com maior nível de escolaridade, saírem de centros urbanos para áreas não tão densamente povoadas onde encontram mais segurança e menos transtornos do que em áreas metropolitanas.

Ao analisar o emprego rural não agrícola e a diversidade rural na América Latina, Dirven (2004, p.51), apresenta cinco definições do que é rural: baseada na população máxima da localidade em torno de 2.000 pessoas, que é utilizada pela maioria dos países; pelo número de habitações contíguas (Peru); pelas definições legais (Brasil, Equador, Guatemala, Uruguai); por encontrar-se fora da "cabeceira municipal” (Colômbia, República Dominicana, El Salvador, Paraguai); e, baseada em "características não rurais" (Costa Rica e Haiti). Nenhum país usa a mesma definição para o que é rural. Segundo Kageyama (2008) todas as definições 
apresentam a ideia de que rural é uma área de baixa densidade populacional e de grandes distancias dos núcleos mais urbanizados.

Pesquisando na literatura internacional indicadores para as regiões rurais, Abramovay (2000) levantou que há diferentes maneiras de classificar o espaço rural no mundo: pode ser pela simples delimitação administrativa, sendo urbanas as sedes dos municípios e distritos (Brasil, Equador, Guatemala, El Salvador e República Dominicana); outros países utilizam o critério de ocupação da mão de obra na agricultura como definição do que é rural, como ocorre no Chile, em Israel e na França; ou, pelo número de habitantes nas sedes municipais (Espanha, Portugal, Itália, Grécia - onde é rural assentamentos humanos contíguos com menos de 10 mil habitantes e tem certo distanciamentos dos centros metropolitanos; e, Argentina, Bolívia, México, Venezuela, Honduras, Nicarágua e Panamá - onde o limite que determina o que é rural varia entre 1.000 e 2.500 habitantes).

Para os europeus, segundo Abramovay (2000), o conceito de ruralidade está cada vez mais ligado à questão da preservação do meio natural, uma vez que, há uma intensificação das políticas e práticas produtivas voltadas à exploração sustentável da biodiversidade. O Istituto Nazionale di Sociologia Rurale (INSOR), citado pelo INEA (2000), classificou o território italiano com base no percentual da "superfície verde" sobre o total da superfície das comunas italianas. Este estudo partiu do pressuposto de que o rural se identifica com um ambiente natural em que a "superfície verde" predomina sobre aquela edificada. Além da "superfície verde", somaram-se as informações sobre densidade populacional para reagrupar as comunas italianas em ruralíssimas, rurais, intermediárias e urbanas. Segundo essa nova tipologia de classificação, foi possível concluir que as comunas rurais e ruralíssimas cobriam $82,9 \%$ das áreas de terras e respondiam por 37,5\% da população italiana. Assim, o meio rural deixa de ser um simples espaço produtivo e passa a ter uma importância social cada vez maior do ponto de vista ambiental, recreativo e residencial. Ou seja, há uma redefinição do que é rural, vinculando este espaço e seus recursos naturais aos interesses da sociedade.

Ao realizar um estudo sobre a organização espacial e a densidade populacional das regiões rurais do sul da Ásia, Qadeer (2000) encontrou locais com densidades populacionais comparáveis as áreas metropolitanas ocidentais. Chamou estes locais de alta densidade populacional de "ruralopolises", ou seja, uma fusão de sistemas econômicos e sociais com organizações espaciais metropolitanas. Este trabalho nos fornece uma referência internacionalmente aceita de que se considera área urbana quando se tem uma densidade igual ou superior a $400 \mathrm{hab} / \mathrm{Km}^{2}$.

Ocaña-Riola e Sánchez-Cantelejo (2005) buscaram uma definição operacional para área rural por meio da construção de um índice de ruralidade para a Espanha, 
que não fosse baseado somente no tamanho da população e na densidade demográfica. As variáveis utilizadas para cada município espanhol foram: a densidade populacional; o número de pessoas com mais de 65 anos por 100 habitantes; número de pessoas com idade entre 0-14 anos por 100 habitantes; número de economicamente inativos por 100 pessoas em idade ativa; número de aposentados por 100 habitantes; número de pessoas que trabalham na agricultura, na criação de gado ou pesca por 100 trabalhadores; número de casas em mau estado ou total ruína por 100 casas.

A seleção dessas variáveis por parte de Ocaña-Riola e Sánchez-Cantelejo (2005), foi justificado por serem representativas do conceito de ruralidade na Espanha. Também porque podem ser medidas, quantificadas, serem de fácil acesso e de atualização imediata. $\mathrm{O}$ índice foi construído a partir de uma análise fatorial de componentes principais, dando origem a um único fator que está correlacionado ao envelhecimento da população, dependência econômica, agricultura, pecuária ou pesca, habitabilidade de habitação e densidade populacional. O envelhecimento da população e a percentagem de menores de 14 anos foram as variáveis que apresentaram um alto grau de correlação com o fator ruralidade.

Segundo Ocaña-Riola e Sánchez-Cantelejo (2005), na Espanha e na União Européia, a ligação entre rural e agrícola está perdendo terreno para um novo conceito de rural relacionado com as atividades de relaxamento, lazer e ao ar livre. Ao longo dos últimos anos, a proteção do ambiente, o desenvolvimento das zonas naturais e a promoção do turismo rural levaram a sociedade a considerar as zonas rurais como um espaço recreativo e ambiental. Esta nova percepção da área rural como destino turístico e de lazer está trazendo recuperação demográfica, econômica e social em áreas que sofreram severo declínio populacional durante o êxodo rural espanhol da década de 1960.

Todas essas delimitações arbitrárias internacionais do que é rural acabam por refletir tradições históricas e geográficas. Isto dificulta a comparação das informações entre os diferentes países devido à falta de homogeneidade nos critérios de definição do que é rural, especialmente se for considerado o simples critério populacional para essa delimitação, conforme pode ser observado nos trabalho de Veiga (2004) para o Brasil.

Para o Brasil, o Instituto Brasileiros de Geografia e Estatística (IBGE, 2010) define como rural a área externa ao perímetro urbano de um distrito, composta por setores nas seguintes situações: rural-de-extensão urbana, rural-povoado, rural-núcleo, rural-outros aglomerados, rural-exclusive aglomerados. Quanto à classificação dos domicílios, o IBGE (2010) classifica-os em oito categorias, sendo três urbanas (Cidade ou vila, área urbanizada; Cidade ou vila, área não urbanizada; 
Área urbana isolada) e cinco rurais (Aglomerado rural de extensão urbana; Aglomerado rural, isolado, povoado; Aglomerado rural, isolado, núcleo; Aglomerado rural, isolado, outros aglomerados; Zona rural exclusive aglomerado rural).

Para Veiga (2004), o Brasil é menos urbano do que o IBGE apresenta se levarmos em consideração as recentes metodologias adotadas no primeiro mundo e se avaliarmos os indicadores disponíveis sobre o que é rural para as sociedades mais desenvolvidas. No Brasil, para Veiga (2002), não deveria ser considerado urbano os municípios com menos de 20 mil habitantes. É um critério de classificação simples e objetivo, mas que falha ao determinar como rural os municípios com grande densidade demográfica situados nas grandes regiões metropolitanas do país. Ao levar em consideração esse critério, Veiga (2002) verificou que dentre os 5.507 municípios existentes no Brasil no ano de 2000, 4.024 municípios seriam considerados rurais.

Kageyama (2008, p.39) discorda dessa classificação simplificada realizada por Veiga (2002). Para Kageyama (2008), o ideal é a combinação de critérios envolvendo população e densidade demográfica, como foi feito por uma pesquisa conjunta entre o Instituto Brasileiro de Geografia e Estatística (IBGE), o Instituto de Pesquisa Econômica Aplicada (IPEA, 2002) e a Universidade Estadual de Campinas (UNICAMP). Segundo Kageyama (2008), com base nos dados do IBGE, IEA e Unicamp, Veiga (2002) classifica de forma equivocada como "urbanos" apenas 455 municípios brasileiros (aglomerações metropolitanas, outras aglomerações e centros urbanos). São classificados como municípios de pequeno porte aqueles que possuem menos de 50 mil habitantes e menos de 80 habitantes por quilômetro quadrado $\left(\mathrm{hab} / \mathrm{Km}^{2}\right)$. Médio porte são aqueles municípios que possuem entre 50 e 100 mil habitantes e mais de $80 \mathrm{hab} / \mathrm{Km}^{2}$. Juntos esses dois grupos totalizam 567 municípios, que adicionados aos 455 anteriores totalizam 1.022 municípios urbanos no Brasil.

\section{PrinCIPAIS CRITÉRIOS UTILIZADOS POR PAÍSES E ORGANIZAÇões PARA DEFINIR ÁREAS RURAIS E URBANAS}

Para os países em desenvolvimento, as áreas rurais são classificadas por Wiggins e Proctor (2001, p. 432) em cinco tipos baseadas em duas variáveis que permitem generalizações úteis a respeito das áreas rurais: abundância de capital natural e pelos custos mais elevados de deslocamentos dos bens e das pessoas. Os custos de movimentações estão diretamente relacionados com a distância da área rural em relação aos centros urbanos. As regiões mais próximas apresentam uma interação mais intensa entre a zona urbana e a rural (zona peri-urbana), permitindo o deslocamento diário das pessoas de uma zona para outra. As áreas rurais mais distantes (rural remoto) não apresentam 
infraestrutura adequada, há dificuldades nos deslocamentos e consequentemente os custos para os fluxos de pessoas e bens são mais elevados. Outra forma de diferenciar as áreas rurais em países em desenvolvimento é a quantidade e qualidade de seus recursos naturais, que podem estimular o desenvolvimento e/ ou atraso da área rural. Normalmente, a dotação dos recursos naturais disponíveis trazem vantagens comparativas para o crescimento econômico da região.

O Quadro 1 apresenta uma série de critérios utilizados na definição das áreas rurais e urbanas para alguns países e organizações do mundo. A maioria dos países latinos americanos utiliza-se de dois critérios: divisão política-administrativa e tamanho da população. A divisão-política administrativa é um critério legal porque o perímetro urbano é delimitado por meio da legislação, e por exclusão do território urbano determina-se o espaço rural, como é o caso brasileiro. O outro critério classificatório utilizado é o tamanho da população de uma localidade, que aparece em países como a Argentina e o México (IBGE, 2017).

Outros países adotam mais de um critério para definição do que é área rural ou urbana, como é o caso da Austrália (utiliza a densidade demográfica, a oferta de serviços e aglomerações de habitações); Chile (tamanho da população e participação da agricultura); Cuba, Honduras, Nicarágua e Panamá (se valem do tamanho da população e oferta de serviços); e, Uruguai (utiliza a oferta de serviços e a divisão administrativa). Somente o Chile utiliza a participação da agricultura como critério para a definição do território em urbano ou rural (IBGE, 2017).

Os países da Organização para Cooperação e Desenvolvimento Econômico (OCDE) e da União Europeia costumam usar a densidade demográfica como critério para classificar as áreas rurais e urbanas, conforme apresentado no Quadro 1. A Organização para Cooperação e Desenvolvimento Econômico (OCDE, 2011), classificou o território de seus países membros em regiões predominantemente rurais, intermediárias e predominantemente urbanas com base na porcentagem de população que vive em unidades rurais locais. A base de dados metropolitana identificou a existência de 1.200 áreas urbanas (com uma população de 50.000 ou mais habitantes) em mais de 30 países da $\mathrm{OCDE}^{4}$. Em 2014, dois terços da população urbana da OCDE viviam em cidades com mais de 50.000 habitantes $^{5}$. Quase metade da população total da $\operatorname{OCDE}(48,2 \%)$ vivia em regiões predominantemente urbanas,

\footnotetext{
${ }^{4}$ Países membros da OCDE em 2011: Alemanha, Austrália, Áustria, Bélgica, Canadá, Chile, Coréia do Sul, Dinamarca, Eslovênia, Espanha, Estados Unidos, Estônia, Finlândia, França, Grécia, Holanda, Hungria, Irlanda, Islândia, Itália, Japão, Luxemburgo, México, Noruega, Nova Zelândia, Polônia, Portugal, Reino Unido, República da Eslováquia, República Tcheca, Suécia, Suíça, Turquia.

${ }^{5}$ No entanto, a experiência urbana é muito diferente de país para país. Na Coréia, $83 \%$ da população nacional estavam concentradas nas cidades (mais de 45 milhões de pessoas).
} 
Quadro 1 - Critérios predominantes utilizados na definição de áreas rurais e urbanas

\section{em países e organizações selecionadas}

\begin{tabular}{|c|c|c|c|c|c|c|}
\hline \multirow[b]{2}{*}{ País/Organização } & \multicolumn{6}{|c|}{ Critérios predominantes utilizados na definição de áreas rurais e urbanas } \\
\hline & $\begin{array}{l}\text { Tamanho da } \\
\text { população }\end{array}$ & $\begin{array}{c}\text { Densidade } \\
\text { demográfica }\end{array}$ & $\begin{array}{c}\text { Oferta } \\
\text { de ser- } \\
\text { viços }\end{array}$ & $\begin{array}{c}\text { Partici- } \\
\text { pação da } \\
\text { agricultura }\end{array}$ & $\begin{array}{l}\text { Divisão admi- } \\
\text { nistrativa }\end{array}$ & $\begin{array}{l}\text { Aglomerações de } \\
\text { habitações }\end{array}$ \\
\hline Argentina & $\mathrm{X}$ & & & & & \\
\hline Austrália & & $\mathrm{X}$ & $\mathrm{X}$ & & & $\mathrm{X}$ \\
\hline Bolívia & $\mathrm{X}$ & & & & & \\
\hline Brasil & & & & & $\mathrm{X}$ & \\
\hline Chile & $\mathrm{X}$ & & & $x$ & & \\
\hline Colômbia & & & & & $\mathrm{x}$ & \\
\hline Costa Rica & & & & & $\mathrm{x}$ & \\
\hline Cuba & $\mathrm{x}$ & & $x$ & & & \\
\hline $\begin{array}{l}\text { República Domi- } \\
\text { nicana }\end{array}$ & & & & & $\mathrm{X}$ & \\
\hline Equador & & & & & $\mathrm{x}$ & \\
\hline El Salvador & & & & & $x$ & \\
\hline Estados Unidos & $\mathrm{x}$ & & & & & \\
\hline França & $\mathrm{X}$ & & & & & \\
\hline Guatemala & & & & & $\mathrm{x}$ & \\
\hline Haiti & & & & & $x$ & \\
\hline Honduras & $x$ & & $x$ & & & \\
\hline Inglaterra & & & & & & $x$ \\
\hline México & $\mathrm{x}$ & & & & & \\
\hline Nicarágua & $x$ & & $x$ & & & \\
\hline País de Gales & & & & & & $x$ \\
\hline Panamá & $x$ & & $x$ & & & \\
\hline Paraguai & & & & & $x$ & \\
\hline Peru & & & & & & $x$ \\
\hline Uruguai & & & $x$ & & $x$ & \\
\hline Venezuela & $x$ & & & & & \\
\hline OCDE & & $X$ & & & & \\
\hline União Européia & & $x$ & & & & \\
\hline
\end{tabular}

Fonte: IBGE (2017), com base em dados de Bibby e Brindley (2013); Brezziet, Dijkstra e Ruiz (2011); Eurostat (2015); Ferranti et al. (2005); IICA (2013). 
o que representava cerca de $6 \%$ da área total. Foram consideradas localidades rurais aquelas que apresentam uma densidade populacional inferior a $150 \mathrm{hab} /$ $\mathrm{Km}^{2}$ (exceto o Japão e Coréia que é de $500 \mathrm{hab} / \mathrm{Km}^{2}$ ). Dessa forma, em 2014, as regiões rurais representavam um quarto $(25,1 \%)$ da população da OCDE e viviam em espaços rurais que cobrem $83 \%$ da área terrestre ${ }^{6}$.

O quarto restante da população da OCDE (26\%) vive nas regiões de categoria intermediária que são chamadas de significativamente ou relativamente rurais. Em todas as três tipos de regiões (urbana, intermediária, rural) encontram-se comunidades rurais e urbanas, só que em diferentes graus. Dessa forma, a OCDE (2011) utiliza uma tricotomia a nível microrregional formada por áreas essencialmente urbanas, essencialmente rurais e uma área ambivalente ou intermediária.

A principal característica da metodologia proposta pela OCDE (2011) é que ela cobre todos os territórios dos países estudados e não apenas suas áreas rurais. Essa metodologia de classificação permite organizar os dados em dois níveis hierárquicos: em unidades locais e a nível regional. Ao realizar essa classificação, é possível estabelecer um critério do que é rural e urbano e assim, ampliamse as condições de analisar a dimensão territorial do desenvolvimento e suas consequências sobre as políticas públicas.

Para a OCDE (2011), localmente as pequenas unidades administrativas podem ser urbanas ou rurais de acordo com sua densidade populacional. Sendo rural quando a densidade populacional for inferior a $150 \mathrm{hab} / \mathrm{Km}^{2}$. O critério de densidade demográfica apresenta como vantagens: a sua fácil operacionalização e compreensão; as áreas rurais sempre serão caracterizadas por apresentar menor densidade habitacional; a densidade populacional é um critério neutro desvinculando a ruralidade da pobreza e do despovoamento.

Regionalmente, segundo a OCDE (2011), basta agregar as unidades locais e classificar a região como predominantemente urbana, intermediária ou predominantemente rural usando a porcentagem da população que vive em unidades locais rurais. Dessa forma, as regiões são classificadas em: predominantemente urbanas (se a participação da população que vive em unidades locais rurais for inferior a 15\%); intermediárias (se a participação da população que vive em unidades locais rurais estiver entre $15 \%$ e 50\%); predominantemente rural (se a participação da população que vive em unidades locais rurais é superior a 50\%).

A OCDE (2011) também realiza uma classificação secundária das regiões levando em consideração a presença ou não de centros urbanos. Uma região predominantemente rural torna-se intermediária se contiver um centro urbano

${ }^{6}$ Essas participações variam conforme o país considerado. Na Irlanda, Finlândia e Eslovênia, a participação da população nacional nas regiões rurais foi duas vezes maior que a média da OCDE. 
de mais de 200.000 habitantes (500.000 para o Japão e a Coréia) representando pelo menos $25 \%$ da população regional. Uma região intermediária torna-se predominantemente urbana se contiver um centro urbano com mais de 500.000 habitantes (1.000.000 para o Japão e a Coréia) representando pelo menos $25 \%$ da população regional.

O trabalho da OCDE (2011) apresenta uma preocupação recorrente para todos aqueles que lidam com o planejamento do território, que é criar uma definição de rural e urbano por meio de critérios ou indicadores (demográficos e sociais) que permitam analisar diferentes espaços em bases homogêneas.

De acordo com o IBGE (2017), houve um esforço nas últimas décadas para o estabelecimento de critérios padrões para a delimitação de áreas rurais e urbanas em escala global e regional. Mas não foi possível essa homogeneização devido à falta de informações a respeitos dos territórios dos diferentes países do mundo.

O que é o espaço rural e urbano para a Itália, França e Estados Unidos

Segundo Cazella, Bonnal e Maluf(2009), a agricultura familiar italiana apresenta uma trajetória de sucesso que comprova o efeito das ações públicas na promoção do desenvolvimento rural. O desenvolvimento rural italiano se dissocia da busca de economia de escala por meio de ganhos de produtividade na atividade agrícola e se aproxima da economia de escopo, ou seja, uma produção de qualidade para atender a um consumidor mais exigente com sua alimentação. Assim, espera-se que o Brasil possa desenvolver políticas públicas para que o espaço territorial brasileiro ocupado pela pequena unidade de produção rural seja capaz de induzir um desenvolvimento rural mais sustentável gerador de novas oportunidades.

Na Itália, de acordo com o Istituto Nazionale di Economia Agraria (INEA, 2000), foram utilizados indicadores que permitem definir o território como um conjunto de relações geográficas, econômicas, sociais e institucionais, entrelaçadas e que se complementam. Assim, a agricultura e os outros setores da atividade econômica passaram a representar os "sistemas territoriais" por grau de homogeneidade de desenvolvimento socioeconômico. Os "sistemas territoriais rurais" representam a integração do setor agrícola com outros setores da economia e com instituições representativas das políticas agrícolas.

Outra metodologia de definição de território utilizado na Itália foi desenvolvida pelo Istituto Nazionale di Statistica (ISTAT, 1986) em parceria com a Universidade de Newcastle e a Universidade de Leeds. Essa nova metodologia permite identificar os trabalhos locais e utiliza o crescimento da importância dos deslocamentos diários da população para trabalhar, chamado movimento "pendularismo". O Istituto Nazionale di Statistica (ISTAT, 1986) denominou esse método de zoneamento 
territorial como sistemas locais de trabalho (SLT). O SLT maximiza o número de pessoas que vivem e trabalham numa mesma área e minimiza o número de trabalhadores que saem diariamente dessa área para trabalhar; e, também, minimiza o número de trabalhadores residentes em outras áreas que entram diariamente para trabalhar. Portanto, o SLT é um sistema de interação local, envolvendo os moradores que trabalham no local, os trabalhadores que saem para trabalhar em outro local e entre os trabalhadores que veem de outra área para trabalhar.

De acordo com o INEA (2000), o SLT de trabalho acaba interferindo na localização de serviços, das atividades econômicas e sociais e na questão da infraestrutura do território. Para Kageyama (2008), os SLT fazem referências às interações entre as comunidades rurais e os centros urbanos. $\mathrm{O}$ objetivo do debate sobre a definição do espaço rural na Itália ajuda a identificar e desencadear as potencialidades de desenvolvimento endógeno dos diferentes sistemas locais de produção. O desenvolvimento rural italiano é o resultado da integração entre agricultura e outras atividades econômicas (artesanato, turismo, pequena empresa de fabricação) e também é a interação dos direitos econômicos, sociais e culturais unidos pela presença de um tecido social e institucional da cultura rural.

O INEA (p.131, 2000) também classificou cada local de trabalho como rural de acordo com os regulamentos da Comissão Europeia. Esse Regulamento utiliza-se da baixa densidade populacional e da elevada importância do setor agrícola. Essa tipologia apresentada pelo INEA (2000), de acordo com Kageyama (p. 46, 2008), resulta em três grandes categorias: os sistemas rurais em declínio; um grupo de áreas com características de ruralidade e com significativa presença de atividades manufatureiras, especialmente agroalimentares (o rural mais dinâmico); e, os sistemas urbanos ou não rurais, com elevada densidade populacional e marcada concentração de indústrias e serviços. Esta classificação constitui uma base para a análise das atividades produtivas em áreas rurais.

Com base nesses sistemas locais de trabalho e manufatura (SLTM), o INEA (p.146, 2000), propõe uma tipologia das áreas rurais italianas combinando seis indicadores econômicos: (1) percentual de empregados na agricultura sobre o emprego total; (2) percentual de empregados em serviços sobre o emprego total; (3) taxa de industrialização (empregados na indústria por 1000 habitantes); (4) presença de atividades comerciais (empregados no comércio por 1000 habitantes); (5) presença de atividades de hospedagem (empregados em hotéis e atividades complementares por 1000 habitantes); e, (6) desenvolvimento do setor bancário (número de agências bancárias por 1000 habitantes).

Por meio de uma análise de clusters, esses indicadores possibilitaram a 
identificação de seis grupos de sistemas econômicos locais para descrever o território: sistema manufatureiro (local com elevada especialização manufatureira, presença significativa de pequenas empresas); sistema turístico (atividades turísticas e recreativas ambientais); sistema agrícola marginal (forte dependência da agricultura e agroindústria de pequeno porte); sistema periurbano (forte presença do setor terciário); sistema agrícola em transição (sistemas rurais do sul da Itália e presença do setor público); sistemas de economia integrada (local com alta taxa de industrialização, forte atividades terciárias, sistema de crédito desenvolvido, áreas urbanas e industriais inseridas em áreas rurais).

No caso italiano, segundo Cazella, Bonnal e Maluf (2009), houve um processo de industrialização difusa

na qual os espaços rurais deixam, de forma gradual, de ser predominantemente agrícolas para evoluírem em direção a um modelo de desenvolvimento regional, estruturado por uma rede urbana de pequenas e médias cidades especializadas na produção de bens e serviços específicos (...). Os espaços rurais, nesse estilo de desenvolvimento, não se reduzem às atividades agrícolas (...), mas são espaços sociais plurissetoriais estruturados por redes produtivas, familiares, profissionais, etc. (CAZELLA, BONNAL E MALUF, p.34. 2009).

A conclusão do estudo do INEA sobre a caracterização da produção nas zonas rurais italianas é de que essas regiões são espaços não somente para a prática da agricultura, mas para o crescimento no número de empregos na indústria manufatureira e nos serviços cada vez mais interagindo com os centros urbanos. Dessa forma, o INEA (2000, p. 154) pode identificar que nas áreas rurais do Centro-Norte apresentaram uma interação maior com os centros urbanos e uma progressiva perda de identidade agrícola, pois apresentaram uma ligação mais forte entre o emprego rural e manufatureiro. Nas áreas rurais do sul da Itália (mais pobres e menos desenvolvidas) há uma especialização nas produções agroindustriais e, portanto, apresenta uma forte conotação agrícola que impacta na estrutura econômica desta região.

Com a finalidade de tornar mais claro o que é rural o Instituto Nacional de Estatísticas e Estudos Econômicos e o Instituto Nacional de Pesquisa Agronômica (Insee/Inra, 1998) da França, realizaram uma nova divisão do que eles chamam de zoneamento em áreas urbanas (ZAU). Assim, foi possível dividir parte do território francês em: pólos urbanos (locais que oferecem ao menos 5 mil empregos e têm uma população entre 8 mil e 10 mil habitantes); e, coroa periurbana (comunas constituídas por ao menos $40 \%$ de pessoas empregadas nos pólos urbanos ou nas 
comunas periurbanas que sofrem influencia destes pólos). De acordo com o Insee/ Inra (1998) 76\% da população francesa vivem nesses espaços de predominância urbana constituído pelos pólos urbanos e comunas periurbanas.

O zoneamento em áreas urbanas realizado pelo Insee/Inra (1998) possibilitou dividir o território francês em quatro categorias de espaços predominantemente rurais: o rural sob fraca influencia urbana (são as bordas em torno dos espaços urbanos constituídos por comunas que tem ao menos $20 \%$ de seus habitantes trabalhando nos centros urbanos); os pólos rurais (são unidades urbanas que oferecem entre 2 mil e 5 mil empregos e possuem mais postos de trabalho do que a população residente. São locais de atração e exercem a função de estruturar o espaço circundante); a periferia dos pólos rurais (são comunas onde menos de $20 \%$ da população ativa trabalha nos pólos rurais); o rural isolado (categoria residual que ainda representa mais de $1 / 3$ do território e $10 \%$ da população francesa).

Este tipo de classificação, desenvolvida pelo Insee/Inra (1998) e utilizada na França, permite uma visão mais assertiva das dinâmicas territoriais, tais como: o seu crescimento demográfico; quais são as áreas de maior atração e repulsão populacional; como ocorrem as relações de confiança entre os habitantes locais e as instituições públicas e privadas; quais os locais que apresentam maiores crescimentos comerciais e industriais; quais as novas atividades econômicas desenvolvidas localmente e no interior das propriedades agrícolas; quais são as atividades que contribuem para a geração de renda em cada território. Dessa forma, é possível acabar com a dicotomia entre cidade e campo ou entre o rural e o urbano, sem abandonar ou deixar de lado as especificidades das áreas rurais.

Ao revisar o desenvolvimento rural norte americano a partir dos anos de 1980, Abramovay (2000) observou que as vantagens comparativas das localidades rurais estavam cada vez mais dependentes da localização destas em relação aos centros metropolitanos. Essa vantagem comparativa cria a possibilidade de uma maior atratividade para atividades de recreação, de um novo local para aposentados e/ou para o estabelecimento de novas residências em locais mais tranquilos que os centros urbanos.

Visto que a maioria dos domicílios rurais não se ocupa com atividades agrícolas, a ideia de continumm rural-urbano de Pahl (1966) passa a fazer sentido nos EUA, uma vez que não há diferenças nos modos de vida, na organização social e na cultura determinados pelos limites espaciais. Também com a redução da agricultura na ocupação produtiva e da dificuldade em separar o que é urbano e rural, fez com que os estatísticos do Serviço de Economia Rural do Departamento de Agricultura dos Estados Unidos (ERS/USDA) ${ }^{7}$ utilizem atualmente a

${ }^{7}$ UNITED STATES DEPARTMENT OF AGRICULTURE (USDA). What is Rural? Disponível em: $<$ https://www.ers.usda. gov/topics/rural-economy-population/rural-classifications/what-is-rural.aspx>. Acesso em: 6 out. 2017. 
classificação dos territórios em áreas metropolitanas e não metropolitanas. Segundo Veiga (2004), ao final do século XX surgiu no mundo outras opções mais relevantes para a abordagem demográfica dos territórios. Os Estados Unidos da América (EUA) utilizam duas formas de classificação oficial, o United States Census Bureau (U.S. Census Bureau) e a do Office of Mangement and Budget (OMB).

O U.S. Census Bureau (2010) classifica as áreas urbanas como aquelas mais adensadas e não segue a divisão político-administrativa. A classificação segue a denominação de áreas urbanizadas ou "clusters" urbanos. Uma área urbanizada caracteriza-se por ter mais de 50 mil pessoas e um núcleo com densidade superior a $386 \mathrm{hab} / \mathrm{Km}^{2}$, podendo ter uma zona adjacente com uma densidade mínima de $193 \mathrm{hab} / \mathrm{Km}^{2}$. Para ser uma área urbanizada não há a necessidade de haver uma cidade com 50 mil habitantes. A partir do censo de 2000 adotou-se o conceito de "clusters" urbanos para aquelas localidades com população ente 50 mil e 2,5 mil habitantes, mas que atinjam os mesmos níveis de densidade demográfica. Dessa forma, para o U.S. Census Bureau (2010), a população rural é aquela que não está classificada como áreas urbanizadas ou "clusters" urbanos. Em 2010, 71,2\% da população americana viviam em 486 áreas urbanizadas (219.922.123 habitantes), 9,5\% em 3.087 “clusters" urbanos (29.331.123 habitantes) e os 19,3\% restantes nas imensas áreas rurais (59.492.267 habitantes).

O Office of Mangement and Budget (OMB, 2003) é um órgão do governo americano com finalidades políticas e administrativas. O OMB (2003) utilizou das estimativas anuais de população, emprego e renda para classificar o território dos EUA em condados metropolitanos (metropolitan counties) e condados não metropolitanos (nonmetropolitan counties). Um condado que contém a maior cidade torna-se o condado central, juntamente com todos os municípios adjacentes que tenham pelo menos $50 \%$ da população na área urbanizada cercando a maior cidade. Um município periférico deve se qualificar com base na porcentagem de residentes empregados do município que trabalham no condado ou condado central. Deve ter um limite mínimo de $25 \%$ dos trabalhadores residentes trabalhando no condado central ou $25 \%$ dos empregados fazendo "padrão de deslocamento reverso" ou pendular reverso onde os trabalhadores se deslocam para locais de trabalho fora de seus municípios de residência. Além disso, os condados não metropolitanos são subdivididos em "micropolitan áreas", centradas em núcleos urbanos com mais de 10 mil habitantes, e "noncore" para o restante dos condados.

O Serviço de Economia Rural do Departamento de Agricultura dos Estados Unidos (ERS/USDA, 2013) utiliza uma mescla das duas classificações normativas oficiais, onde foi possível classificar em "metro" e "nonmetro" os residentes das 
áreas rurais e urbanas dos EUA, de acordo com os dados do censo de 2000. Para o ERS/USDA (2013), a população "nonmetro" divide-se em 58,9\% rural e 41,1\% em urbana. Já a população "metro" está constituída por $21 \%$ rural e $79 \%$ urbana.

Nos EUA a dicotomia urbano-rural foi substituída pelo U.S. Census Bureau por uma tricotomia em "áreas urbanizadas", "clusters urbanos" e "áreas rurais". A OMB (2000) preferiu uma nova dicotomia "metro" e "nonmetro". E, para efeitos analíticos, o ERS/USDA optou pela classificação dicotômica dos dados do $U$. S. Census Bureau. Ou seja, os formuladores de políticas públicas dos EUA, muitas vezes, acabam por criar suas próprias definições do que é rural e não rural.

\section{O QUE É RURAL OU URBANO PARA O BRASIL}

Para determinar o que é rural e urbano no Brasil, Veiga (2004), utilizou-se das estatísticas demográficas e procurou entender porque ainda existe essa contradição urbano-rural no Brasil no início do século XXI. Os indicadores demográficos que mais confirmam a atualidade da dicotomia rural e urbano é o número de homens serem persistentemente maior ao número de mulheres e a fertilidade entre as mulheres ser superior nas regiões rurais do Brasil. No entanto, para Veiga (2004) a maior fertilidade entre as mulheres e a predominância masculina não são razões suficientes para se pensar que esta seja a principal fronteira espacial entre o urbano e o rural.

Segundo Abramovay (1999), o fluxo migratório de jovens do meio rural tem causado problemas de masculinização do campo; inserção no mercado de trabalho urbano de baixa qualificação; desertificação social, econômica e cultural das áreas de pequena concentração populacional; e, aumento do custo social e ambiental para os centros urbanos. Para reverter este fluxo migratório dos jovens do meio rural para o meio urbano o Brasil tem que criar condições para que os jovens permaneçam na atividade produtiva por meio do desenvolvimento do espaço rural, respeitando as particularidades de cada território. Com a promoção do desenvolvimento do espaço rural, haverá ampliação da relação campo e cidade, tendo como consequência o surgimento de novas oportunidades para a melhoria nas condições de vida no meio rural.

Para Veiga (2004), o Brasil é mais rural do que oficialmente se divulga, pois cerca de $80 \%$ dos municípios brasileiros e $30 \%$ da população estão em ambiente rural. Essa observação reforça que ainda existe uma contradição urbano-rural no Brasil, principalmente se forem consideradas as diferentes atividades desenvolvidas em muitas áreas rurais e que não tem relação direta com as atividades agropecuárias. Outro ponto que deve ser considerado é o tamanho do território brasileiro e as desigualdades apresentadas pelas diferentes regiões rurais do país, localizadas na 
região amazônica, da mata atlântica, dos campos e das florestas meridionais.

Segundo Veiga (2004), o conceito brasileiro de urbano como sendo toda a área sede município (cidade) e de distrito (vila), independente de suas características estruturais ou funcionais, é uma forma simples e equivocada de classificação que deixa o Brasil com 81,2\% de urbanização. Para o autor, devem ser estabelecidos critérios mais objetivos e assertivos de classificação em urbano e rural. Um critério seria adotar o número de habitantes, a densidade demográfica e a localização do município analisado, que pode ser próximo a regiões metropolitanas e outras aglomerações urbanas regionais.

Partindo desses critérios (população, densidade e localização) o desafio foi classificar a população dos 5.507 municípios brasileiros pesquisados pelo Censo de 2000. Como apoio para seu trabalho, Veiga (2004) adotou como urbana a população da pesquisa apresentada na Série Caracterização e Tendência da Rede Urbana do Brasil (1999 e 2002) desenvolvida pelo Instituto de Pesquisa Econômica Aplicada (Ipea); Instituto Brasileiro de Geografia e Estatística(IBGE)/Universidade Estadual de Campinas (Unicamp)/ Núcleo de Economia Social, Urbana e Regional (Nesur) onde foram identificados 455 municípios (12 aglomerações metropolitanas, 37 demais aglomerações e 77 centros urbanos) urbanos e que representavam $57 \%$ da população do Brasil no ano de 2000.

O desafio era classificar os 5.052 municípios que não foram englobados pelas aglomerações urbanas da Série Caracterização e Tendência da Rede Urbana do Brasil (1999 e 2002). Para resolver este problema, Veiga (2004) utilizou como critério decisivo a densidade demográfica ${ }^{8}$. Veiga (2004) estabeleceu que uma densidade de $80 \mathrm{hab} / \mathrm{Km}^{2}$ como o limite em que um território deixaria de pertencer a categoria rural e passaria a categoria de urbano. Essa densidade de $80 \mathrm{hab} / \mathrm{Km}^{2}$ justifica-se pela observação da evolução da densidade demográfica conforme diminui o tamanho da população do município. Segundo Veiga (2004),

enquanto nos municípios com mais de 100 mil habitantes, considerados centros urbanos pela citada pesquisa Ipea/IBGE//Unicamp, a densidade média é superior a $80 \mathrm{hab} / \mathrm{Km}^{2}$, na classe imediatamente inferior (entre 75 e 100 mil habitantes) ela desaba para menos de 20 hab/km². Fenômeno semelhante ocorre entre as classes superior e inferior a 50 mil habitantes (50-75 mil e 20-50 mil), quando a densidade média torna a cair, desta vez para $10 \mathrm{hab} / \mathrm{Km}^{2}$. (VEIGA, p. 79, 2004).

\footnotetext{
${ }^{8}$ Segundo Veiga (2004), a densidade demográfica é o melhor indicador para demonstrar as modificações promovidas pelo homem no ambiente natural. Ou seja, a "pressão antrópica" e o grau de artificialização dos ecossistemas.
} 
Assim, Veiga (2004) considerou município de pequeno porte os municípios que apresentaram menos que 50.000 habitantes e menos que $80 \mathrm{hab} / \mathrm{Km}^{2}$; e de médio porte aqueles municípios entre 50 e 100 mil habitantes cuja densidade seja maior que $80 \mathrm{hab} / \mathrm{Km}^{2}$, mesmo que tenham uma população inferior a 50 mil habitantes.

Por meio da análise desses resultados foi que Veiga (2004) concluiu que o Brasil rural é formado por $80 \%$ dos municípios brasileiros, nos quais reside $30 \%$ da população brasileira. Também foi possível constatar que $13 \%$ da população brasileira que vive em $10 \%$ dos municípios não se enquadra como essencialmente urbano e nem essencialmente rural. Portanto, o Brasil urbano é constituído por 455 municípios. Os demais 4.485 municípios do Brasil rural são vilarejos e as sedes dos 567 municípios intermédios são vilas, que poderão se transformar em cidades.

Dessa forma, Veiga (2004) separou os municípios brasileiros em cinco grupos: três grupos (aglomerações metropolitanas; demais aglomerações; centros urbanos) constituintes da rede urbana do Ipea/IBGE/Unicamp e os outros municípios foram separados em dois grupos pelos critérios de localização, tamanho e densidade em "ambivalentes" e "rurais". Por meio desse critério, Veiga (2004) estimou que em média 4.502 sedes de municípios brasileiros são "cidades imaginárias", por não apresentarem indicadores de serviços urbanos, alguns essenciais.

Outro critério utilizado por Veiga (2004) foi à análise da distribuição populacional das microrregiões. Para tanto, utilizou-se o critério da densidade demográfica ( 80 $\mathrm{hab} / \mathrm{Km}^{2}$ ) para classificar as microrregiões de governo brasileiras. Constatou que das 558 microrregiões brasileiras: 388 apresentam menos que $80 \mathrm{hab} / \mathrm{Km}^{2}$ e 32 apresentam mais de $80 \mathrm{hab} / \mathrm{Km}^{2}$. As demais microrregiões foram classificadas em metropolitanas (22) e não-metropolitanas (41). As 32 microrregiões com mais de 80 $\mathrm{hab} / \mathrm{Km}^{2}$ apresentam um significativo grau de urbanização, mesmo sem a presença de um município com mais de 100 mil habitantes como se utilizou o Ipea/IBGE/ Nesur-IE/Unicamp para definir o que é um centro urbano.

Para refinar mais ainda o que é rural e o que é urbano no Brasil, Veiga (2004), agrupou os cinco tipos de microrregiões em três grandes categorias: microrregiões marcadas por aglomerações urbanas (metropolitanas e não-metropolitanas); microrregiões significativamente urbanizadas (com centros urbanos ou com mais de $80 \mathrm{hab} / \mathrm{Km}^{2}$ ); e, microrregiões predominantemente rurais (sem aglomerações, sem centro urbano e com menos de $80 \mathrm{hab} / \mathrm{Km}^{2}$ ). Das 558 microrregiões brasileiras: 388 apresentaram-se como predominantemente rurais (30,9\% da população brasileira);

\footnotetext{
${ }^{9}$ Veiga (2004) classificou 4.502 sedes de municípios como “cidades imaginárias” por não disporem das seguintes funções urbanas: sem serviço de esgotamento sanitário terceirizado; sem manutenção e estradas e vias terceirizadas; sem varredura de ruas e limpeza terceirizada; sem museu; sem plano diretor; sem guarda municipal; sem teatro ou casa de espetáculo; sem IPTU progressivo; sem instituição de ensino superior; sem estação de Rádio AM; sem coleta de lixo domiciliar terceirizada; sem provedor de internet; sem lei de zoneamento ou equivalente; sem página na internet.
} 
107 como significativamente urbanizadas (20,1\% da população brasileira); e, 63 marcadas por aglomerações (63\% da população brasileira).

Assim, Veiga (2004) conclui que o peso relativo da população rural no Brasil, no ano de 2000, era de aproximadamente $30 \%$ ou o equivalente aos 4.500 municípios que não dispõem de funções que indicam grau de urbanização. Ficou demonstrado pelas duas metodologias, a de análise municipal e pela de microrregiões, que o Brasil apresenta 30\% de sua população rural.

Por meio de suas observações e configurações, Veiga (2004) comprovou sua hipótese de que o Brasil é mais rural do que os dados populacionais apresentados pelo IBGE, onde se considera urbano toda a sede de município. Dessa forma foi possível chegar a um resumo da hierarquia urbano-rural sobre o Brasil: $50 \%$ da população brasileira é urbana; $20 \%$ é ambivalente; e, $30 \%$ é rural.

O Brasil é mais rural do que oficialmente se calcula pelo simples método de se considerar urbano toda a sede de município. O mundo rural brasileiro está constituído por aproximadamente $80 \%$ dos municípios, $70 \%$ das microrregiões, $60 \%$ do território nacional e por $30 \%$ da população do país.

\section{Considerações Finais}

Este trabalho objetivou apresentar um levantamento de quais critérios o Brasil e o mundo utilizam para definir o que é um espaço rural e um espaço urbano, com a finalidade de ajudar os elaboradores de políticas públicas específicas para cada território. Nesse sentido tanto os trabalhos da OCDE (2011), do ERS/USDA (2010) e do Insee/Inra (1998) procuraram pensar o espaço rural como um local para o desenvolvimento social. Em todos esses estudos houve a preocupação em elaborar uma definição espacial para o que é rural e urbano e não apenas setorial. Os resultados desses trabalhos mostram que há uma preocupação em detalhar melhor os espaços e, isso resultou numa reclassificação do rural nos EUA, na França e em alguns países membros da OCDE. Todos esses trabalhos destacam a importância das cidades rurais e a integração dos diferentes setores econômicos para o desenvolvimento do território. Também se torna difícil estabelecer um padrão de classificação para o que é rural, devido à grande diversidade que é característica desse espaço territorial.

O desenvolvimento rural tem que ser concebido de forma mais intensa no espaço territorial por meio de uma maior integração entre a agricultura e as atividades econômicas urbanas (indústria, comércio, serviços). Devem-se criar condições para que os habitantes daquele espaço territorial passem a valorizar mais a diversidade de atividades e mercados possíveis de serem constituídos de 
forma integrada. Para que isso aconteça, pressupõe-se a aprovação de políticas públicas que estimulem projetos que valorizam o local dentro de um processo de desenvolvimento econômico e social. Nos EUA, Itália e França e nos países desenvolvidos da OCDE, os empregos agrícolas estão em declínio, mas quando analisados os domicílios rurais constatou-se que mais de $90 \%$ dos domicílios não são unidades de produção agropecuária. Ou seja, a maioria dos empregos de quem mora no meio rural está em outros setores da economia, como o industrial e de serviços (OCDE, 2011).

Em quase todo o mundo, as estatísticas nacionais definem o rural como oposição, complemento ou resíduo do urbano. Para o Brasil, o problema de classificação do que é rural e urbano sofre influências desde 1938, onde se definiu "cidade" como a sede do município, e, ainda possibilita-se aos municípios determinar o que é rural e urbano pela Lei do Perímetro Urbano Municipal. A consequência de a liberdade dos municípios determinarem o que é urbano causou um exagero sobre o grau de urbanização dos territórios, sendo considerados urbanas todas as sedes municipais, distritos e vilas (KAGEYAMA, 2008).

O Brasil é uma nação em que tantas pessoas vivem em áreas que não são claramente rurais ou urbanas. Mudanças aparentemente pequenas na forma como as áreas rurais são definidas podem ter grandes impactos sobre quem e o que são considerados rurais. Os pesquisadores e os formuladores de políticas públicas compartilham a tarefa de escolher adequadamente entre as definições rurais alternativas atualmente disponíveis ou criar suas próprias definições do que é rural e não rural (VEIGA, 2004).

Ao contrário do que se pensa no Brasil, o crescimento dos centros urbanos não leva necessariamente a uma melhor distribuição de renda e a redução do nível de pobreza da população que neles vivem. Nesse aspecto, o espaço rural permite uma série de oportunidades de geração de renda (produção primária, processamento dos produtos, serviços e comércio) capazes de promover uma maior integração das populações e a um custo de investimento menor que o setor industrial. Transformar essa possibilidade de melhorias nas condições de vida das pessoas desse espaço territorial em realidade passa pelo processo de valorização do meio rural através de políticas públicas que favoreçam a um maior entrelaçamento do rural com o urbano (ABRAMOVAY, 1999).

\section{REFERÊNCIAS}

ABRAMOVAY, Ricardo. Agricultura familiar e desenvolvimento territorial. 
Revista da Associação Brasileira de Reforma Agrária, v.28, n.1, 1999.

ABRAMOVAY, Ricardo. Funções e medidas da ruralidade no desenvolvimento contemporâneo. Instituto de Pesquisas Econômicas Aplicadas (IPEA): Rio de Janeiro, 2000. Texto para discussão n.72.

CAZELLA, Ademir A.; BONNAL, Philippe; MALUF, Renato S. In: CAZELLA, Ademir A.; BONNAL, Philippe; MALUF, Renato S. (Org.). Multifuncionalidade da agricultura familiar no Brasil e o enfoque da pesquisa. Rio de Janeiro: Mauad X, 2009, p.47-70.

DIRVEN, Martine. El empleo rural no agrícola y la diversidad rural en América Latina. Revista de la CEPAL, v.83, ago. 2004, p.49-69.

ECONOMIC RESEARCH SERVICE OF UNITED STATES DEPARTMENT OF AGRICULTURE (ERS/USDA). Nonmetro Counties are Commonly Used to Depict Rural and Small-Town Trends. 2013. Disponível em: < https://www. ers.usda.gov/topics/rural-economy-population/rural-classifications/what-is-rural. aspx>. Acesso em: 08 mar 2019.

INSTITUTO BRASILEIRO DE GEOGRAFIA E ESTATÍSTICA (IBGE). Atlas do Censo Demográfico de 2010. Disponível em: < https://censo2010.ibge.gov.br/ apps/atlas/>. Acesso em: 12 out 2017.

INSTITUTO BRASILEIRO DE GEOGRAFIA E ESTATÍSTICA (IBGE). Classificação e Caracterização dos Espaços Rurais e Urbanos do Brasil: uma primeira aproximação. (IBGE - Coordenação de Geografia). Rio de Janeiro: IBGE, 2017. 94p.

INSTITUTO DE PESQUISA ECONÔMICAAPLICADA(IPEA). Caracterização e tendências da rede urbana do Brasil. Brasília: Ipea, 2002. 206p. v.6

INSTITUTO NACIONAL DE ESTATÍSTICAS E ESTUDOS ECONÔMICOS/ INSTITUTO NACIONAL DE PESQUISA AGRONÔMICA - INSEE/INRA. Les campagnes et leurs villes: contours et caracteres. Insee/Inra: Paris, n.4 1998, p. 885-886. 
ISTITUTO NAZIONALE DI ECONOMIAAGRÁRIA - INEA. Tipologie di aree rural in Italia. Roma: Studi \& Ricerche. INEA, 2000. 175p.

ISTITUTO NAZIONALE DI STATISTICA - ISTAT. Classificazione dei comuni secondo le caratteristiche urbane e rurali, Note e Relazioni. Roma, 1986. Disponível em: <http://www.istat.it/it/archivio/6789>. Acesso em 22 out. 2017. KAGEYAMA, Ângela. Cadernos de Ciência \& Tecnologia, Brasília, v.21, n.3, p.379-408, set./dez. 2004.

KAGEYAMA, Ângela. Desenvolvimento rural: conceitos e aplicação ao caso brasileiro. Porto Alegre: Editora da UFRGS: Programa de Pós-Graduação em Desenvolvimento Rural, 2008.

OCAÑA-RIOLA, Ricardo; SÁNCHEZ-CANTELEJO, Carmen. Rurality Index for small áreas in Spain. Social Indicators Research, n.73, 2005, p. 247-266.

OFFICE OF MANAGEMENT OF BUDGET (OMB). Final Report and Recommendations From the Metropolitan Area Standards Review Committee to the Office of Management and Budget Concerning Changes to the Standards for Defining Metropolitan Areas - 2000. Disponível em: $<$ https://obamawhitehouse. archives.gov/ sites/default/files/omb/inforeg/metro2000.pdf $>$. Acesso em: 11 out 2017.

OFFICE OF MANAGEMENT OF BUDGET (OMB). Metropolitan Statistical Areas; Micropolitan Statistical Areas; Combined Statistical Areas; New England City and Town Areas; Combined New England City and Town Areas - 2003. OMB Bulletin 3-4, 2003. Disponível em: <https://www.whitehouse.gov/sites/ whitehouse.gov/files/omb/assets/OMB/bulletins/b03-04_attach.pdf $>$. Acesso em: 4 out 2017.

ORGANIZATION FOR ECONOMIC CO-OPERATION AND DEVELOPMENT (OCDE). OCDE regional typology. Directorate for Public Governance and Territorial Development. Paris: OECD, 2011. 16 p. Disponível em: <http://www. oecd.org/gov/regional-policy/OECD_regional_typology_Nov2012.pdf > . Acesso em: 2 out. 2017. 
Governance and Territoral Development. 2011. Disponível em: $<$ http://www.oecdilibrary.org/docserver/d/3015041e.2\&id=id\&accname=guest\&checksum=B7607B B29437C0D399C9A8768BC631E9>. Acesso em: out 2017.

PAHL, Ray E. The rural-urban continuum. Sociologia Ruralis, v.6, n.3-4, p.229329, 1966.

QADEER, Mohammad. A. Ruralopolises: The Spatial Organization and Residential Land Economy of High-density Rural Regions in South Asia. Urban Studies, v.37, n.9, 2000, p.1583-1603.

UNITED STATES CENSUS BUREAU (U.S. CENSUS BUREAU). 2010 Census Urban and Rural Classification and Urban Area Criteria. Disponível em: $<$ https://www.census.gov/geo/reference/ua/urban-rural-2010.html $>$. Acesso em: 1 out 2017.

UNITED STATES DEPARTMENT OR AGRICULTURE (USDA). What is Rural? Disponível em: $<$ https://www.ers.usda.gov/topics/rural-economy-population/ruralclassifications/what-is-rural.aspx>. Acesso em: 6 out. 2017.

VEIGA, José Eli da. Cidades Imaginárias: o Brasil é menos urbano do que se calcula. Campinas/SP: Autores Associados, 2002. 304p.

VEIGA, José Eli da. A dimensão rural do Brasil. Estudos Sociedade e Agricultura, v.12, n.1, 2004, p.71-94.

WIGGINS, Steve; PROCTOR, Sharon. How special are rural áreas? The economic implications of location for rural. Development Policy Review, v.19, n.4, 2001. 